\title{
Transparência Fiscal dos Sítios Virtuais das Prefeituras da Microrregião de Salgueiro: da obrigatoriedade à accountability
}

\author{
Luzania Alves de Sousa ${ }^{1}$; Cícero Alves Oliveira ${ }^{2}$; Júlio João de Oliveira ${ }^{3}$; \\ Francildo Galvão ${ }^{4}$; Hesler Piedade Caffé Filho ${ }^{5}$
}

\begin{abstract}
Resumo: A pesquisa trata da disponibilização das peças orçamentárias nos sítios virtuais dos municípios da microrregião de Salgueiro, no Sertão central de Pernambuco. Busca-se investigar qual a aplicabilidade das peças orçamentárias dos sítios virtuais das prefeituras da microrregião de Salgueiro, à luz dos principais comandos normativos sobre transparência fiscal. Os objetivos buscam quais municípios possuem sites na internet para publicação das peças orçamentárias; se há barreiras à consulta pública e quais municípios divulgam as peças conforme o artigo 48 da LC 101/00. É um estudo exploratório, com abordagem qualitativa no que se refere à consulta aos sites de Cedro, Mirandiba, Parnamirim, Salgueiro, São José do Belmonte, Serrita e Verdejante e busca aferir o nível de aderência dos municípios às diretrizes sobre transparência fiscal. Quanto à análise dos dados é um levantamento que usa a abordagem qualitativa. O estudo permite a elaboração de tabelas e gráficos extraindo do caput do artigo 48 da $\mathrm{LC} \mathrm{n}^{\mathrm{o}} 101 / 00$ as categorias de análise. O referencial teórico trata da necessidade legal da gestão pública pautar-se nos princípios da publicidade e transparência. O estudo revela uma situação crítica quanto à publicização do PPA, da LDO e da LOA desses municípios. Recomenda-se o aprofundamento do tema para que a microrregião supere o baixíssimo nível de aderência às normas brasileiras na promoção da publicidade e transparência na gestão dos recursos públicos.
\end{abstract}

Palavras-Chave: transparência fiscal, orçamento público, sítios virtuais, prefeituras, microrregião de Salgueiro, accountability.

\section{Transparency of Virtual Sites of City Halls of Salgueiro Microregion: From the Obligation to Accountability}

\begin{abstract}
The research deals with the availability of budget components in the virtual sites of the municipalities of the micro-region of Salgueiro, at the central hinterlands of Pernambuco. It is sought to investigate the applicability of the budget components of the virtual sites of the prefectures of the Salgueiro microregion, in light of the main normative commands on fiscal transparency. The objectives are to find out which municipalities have websites to publish budget components; If there are barriers to public consultation and which municipalities disclose the pieces according to article 48 of LC 101/00. It is an exploratory study, with a qualitative approach regarding the consultation of the sites of Cedro, Mirandiba, Parnamirim, Salgueiro, São José do Belmonte, Serrita and Verdejante and seeks to measure the level of adherence of the municipalities to the guidelines on fiscal transparency. As for the data analysis is a survey that uses the qualitative approach. The study allows the elaboration of tables and graphs extracting the categories of analysis from the caput of article 48 of $\mathrm{LC}^{\circ}{ }^{\mathrm{o}} 101 / 00$. The theoretical framework deals with the legal need for public management to be guided by the principles of publicity and transparency. The study reveals a critical situation regarding the publicity of the PPA, the LDO and the LOA of these municipalities. It is recommended to deepen the theme so that the micro-region surpasses the very low level of adherence to Brazilian norms in promoting publicity and transparency in the management of public resources.
\end{abstract}

Keywords: Applicability, budget pieces, virtual sites, prefectures, Salgueiro Microregion, fiscal transparency.

\footnotetext{
${ }^{1}$ Licenciada em Letras pela Faculdade de Ciências Humanas do Sertão Central - FACHUSC, Bacharela em Direito pela FACHUSC, Graduanda em Administração Pública pela UNIVASF, Especialista em Programação do Ensino de Língua Portuguesa pela Universidade de Pernambuco - UPE e Professora do Estado de Pernambuco - luzania2010@ gmail.com

${ }^{2}$ Graduando em Administração Pública pela UNIVASF - www.pitta16@bol.com.br

${ }^{3}$ Graduando em Administração Pública pela UNIVASF - julioises@ gmail.com

${ }^{4}$ Graduando em Administração Pública pela UNIVASF - francildo.galvao@ hotmail.com

${ }^{5}$ Mestre em Gestão de Políticas Públicas pala Universidade Federal do Recôncavo da Bahia - UFRB e Professor do Bacharelado em Adm. Pública da Universidade Federal do Vale do São Francisco - UNIVASF - hesler.caffe@ univasf.edu.br
} 


\section{Introdução}

Na esfera municipal, o Poder Executivo tem na pessoa do prefeito a legitimação do processo representativo para a gerência do município de forma a zelar pela prestação de serviços públicos de qualidade para todos os munícipes. De acordo com a Constituição Federal de 1988 (caput do artigo 37), o poder público, legalmente instituído para administrar uma coletividade, precisa apropriar-se de parcela da riqueza produzida por essa coletividade com vistas a devolver-lhe uma prestação de serviço pautada nos princípios constitucionais da legalidade, impessoalidade, moralidade, publicidade e eficiência (BRASIL, 1988).

Nesse contexto, o orçamento público surge como um instrumento para a concretização de uma gestão governamental que trabalhe no sentido de melhorar a vida da coletividade a quem o mesmo deve servir. $O$ artigo é o resultado de um estudo que revela que o acompanhamento da arrecadação e da despesa pública carece de controle social e que não deve se apresentar de difícil acesso para a população.

O estudo aponta que, a partir de tais pressupostos, a publicização e divulgação do processo orçamentário são consequências de um governo municipal que busca exercer a transparência fiscal não apenas para cumprir os dispositivos legais obrigatórios aos gestores públicos, como o que regulamenta o artigo 48 da Lei de Responsabilidade Fiscal, mas como uma forma de prestação de contas aos interessados diretos, ou seja, uma accountability que visa os munícipes em primeira instância. No entanto, a disponibilização de peças orçamentárias, em diferentes níveis da gestão governamental, ainda se apresenta como dificuldade para que a população venha a participar do acompanhamento da despesa pública.

\section{Justificativa}

Tal investigação se justifica porque a gestão da coisa pública deve se dar pautada em princípios como a publicidade e a transparência. A relevância do estudo se justifica sob o enfoque científico quando se busca compreender o que é o orçamento público e por que se deve conhecer o processo orçamentário, desde o planejamento até a sua execução; e, sob o 
enfoque social, a importância está na necessidade de o cidadão ser capaz de discutir e se tornar parte ativa nas discussões acerca dos gastos públicos.

A pesquisa visa contribuir para identificar quais municípios, dentre os sete, que integram a microrregião de Salgueiro, trabalham na construção e execução do orçamento público como um instrumento acessível ao acompanhamento e às discussões sociais de forma que o gasto público venha a garantir uma melhor qualidade de vida para a população dessa microrregião.

\section{Contextualizando a temática e a definição do problema}

A pesquisa tem como objeto de estudo a disponibilização das peças orçamentárias em sítios eletrônicos dos municípios da microrregião de Salgueiro, na região do Sertão central de Pernambuco. O acesso ao PPA, à LDO e à LOA trouxe dificuldade acentuada para os alunos da disciplina de Orçamento Público, no bacharelado em Administração Pública BAP/UNIVASF, quando os mesmos precisaram buscar a publicação da Lei do PPA dos municípios onde moram, momento no qual se evidenciou que, em alguns municípios, não é tarefa tão fácil encontrar essas publicações.

Assim, busca-se investigar: qual a aplicabilidade das peças orçamentárias dos sítios virtuais das prefeituras da microrregião de Salgueiro, à luz dos principais comandos normativos sobre transparência fiscal. Por conseguinte, os resultados da investigação podem contribuir para que a microrregião de Salgueiro venha a aperfeiçoar o modelo de orçamento que os municípios de sua circunscrição praticam.

\section{Objetivos}

Como objetivo geral, a pesquisa investiga como os municípios da microrregião de Salgueiro divulgam as peças orçamentárias nos sítios virtuais das prefeituras. Ao passo que os objetivos específicos visam: a) buscar quais municípios da microrregião possuem portais de consulta na internet para publicação das peças orçamentárias; b) investigar se há barreiras à consulta pública das peças orçamentárias e c) identificar quais dos sete municípios divulgam 
as peças orçamentárias, conforme o exigido pelo artigo 48 da Lei de Responsabilidade Fiscal para assegurar ao cidadão/usuário o acesso à informação orçamentária para acompanhamento da despesa pública.

\section{Metodologia}

Nesta sessão, apresenta-se o enquadramento metodológico da pesquisa, bem como os procedimentos de coleta e análise de dados.

\section{Tipo de Pesquisa}

A pesquisa é um estudo exploratório, com abordagem qualitativa no que se refere à consulta aos portais dos municípios de Cedro, Mirandiba, Parnamirim, Salgueiro, São José do Belmonte, Serrita e Verdejante, que integram a microrregião de Salgueiro. A investigação visa explorar os suportes virtuais que as prefeituras dos municípios desta microrregião utilizam para divulgar suas peças orçamentárias. Tal exploração busca aferir o nível de aderência dos municípios às diretrizes do caput do artigo 48 da Lei Complementar $\mathrm{n}^{\circ}$ 101/2000 no que tange à transparência fiscal.

Dessa forma, a pesquisa se desenvolve a partir de buscas nos sítios eletrônicos das prefeituras dos sete municípios integrantes da microrregião de Salgueiro com vistas a identificar se o município possui site que viabilize o cumprimento legal na divulgação das peças orçamentárias para acesso/consulta popular.

\section{Instrumentos Utilizados}

Esse estudo é realizado em várias etapas que, no conjunto, constituem trabalho harmônico e coordenado. Na visão de Piovesan e Temporini (1995), cada etapa se apoia nos resultados obtidos na etapa anterior. Em relação aos procedimentos, trata-se de levantamento de dados nos sítios eletrônicos dos municípios da microrregião de Salgueiro buscando a 
efetivação da governabilidade transparente na publicação das peças orçamentárias com base no disposto no caput do artigo 48 da $\mathrm{LC}^{\circ}$ 101/00.

Quanto à análise dos dados, utiliza-se a abordagem qualitativa. De acordo com Richardson (1999), os estudos que empregam uma metodologia qualitativa podem descrever a complexidade de determinado problema, analisar a interação de certas variáveis, compreender e classificar processos dinâmicos vividos por grupos sociais.

O estudo permite a elaboração de tabelas e gráficos extraindo do caput do artigo 48 da LC $n^{\circ} 101 / 00$ as categorias e subcategorias de análise. Para análise do nível de aderência dos municípios às categorias recorre-se ao barema elaborado por Braga (2015) para pontuar as subcategorias, que integram as duas categorias pesquisadas, avaliadas através de uma escala estruturada de três pontos, sendo zero para o não-atendimento, um ponto para atendimento parcial e dois pontos para o atendimento integral.

\section{Referencial Teórico}

O referencial teórico retoma conceitos significativos sobre a Administração Pública, trata da transparência como desdobramento do princípio constitucional da publicidade conforme o caput do artigo 37 da $\mathrm{CF} / 88$. São apresentadas considerações sobre o Plano Diretor Municipal, o planejamento e a Gestão Pública municipais uma vez que a coleta de dados e os resultados encontrados tomam os sítios virtuais das prefeituras da microrregião de Salgueiro para investigação acerca da divulgação das peças orçamentárias. Aborda-se a democracia e o orçamento participativos para a consecução da implantação de orçamentos públicos cujas peças orçamentárias possam estar ao alcance popular com vistas à promoção da publicidade e transparência fiscal.

\section{Administração Pública}

As contribuições que serviram de base para a formação da Ciência da Administração vieram das mais variadas fontes. De acordo com Jacobsen e Moretto Neto (2012), 
inicialmente, temos as experiências vividas por povos das civilizações antigas, passando pelos princípios praticados por instituições como a Igreja Católica e a organização militar e chegando a figuras de destaque como Charles Babbage, Adam Smith, Frederick Taylor, Henry Ford, entre tantos outros.

Trigueiro e Marques (2012) afirmam que os acontecimentos ocorridos, principalmente após o final dos anos 80, consolidaram o processo de globalização da economia, o que provocou mudanças na forma de administrar as empresas públicas, privadas e do terceiro setor. Conceituar a Administração Pública requer o entendimento sobre o que vem a ser o Estado com destaque para a visão fornecida por Bresser-Pereira que considera o Estado como uma organização burocrática estatal que tem poder particular para definir leis e tributar os habitantes de um território, sendo dirigida por um governo e dotada de um corpo burocrático e de uma força pública (JUNQUILHO, 2012).

Para compreender a Administração Pública de forma mais ampla, Junquilho (2012) recorre aos ensinamentos de Bobbio, Mattteucci e Pasquino que a consideram o conjunto de atividades destinadas à execução das tarefas ou incumbências de interesse público ou comum, numa coletividade ou organização estatal; ao que seguem considerações sobre Estado unitário e federativo (JUNQUILHO, 2012), sendo este último, o caso brasileiro.

\section{Plano Diretor, Planejamento e Gestão Pública Municipais}

A Lei $n^{\circ}$ 10.257/01 - Estatuto da Cidade, regulamentou o Capítulo II da Constituição Federal de 1988. Essa Lei estabelece normas de ordem pública e interesse social que regulam o uso da propriedade urbana em prol do bem coletivo, da segurança e do bem-estar dos cidadãos, bem como do equilíbrio ambiental. (BRASIL, 2001, art. $1^{\circ}$, parágrafo Único). Planejar democraticamente o futuro da cidade incorporando nessa discussão os diversos agentes sociais, econômicos e políticos que a compõem, buscando compromissos e definindo ações prioritárias; esse é o desafio que o Estatuto da Cidade impõe aos planos diretores (REZENDE, 2007).

A Lei 10.257/01 instrumentaliza a elaboração do Plano Diretor para as cidades com mais de 20 mil habitantes como preceitua a CF de 1988 e apresenta as ferramentas para que a 
organização dos municípios se fundamente, entre outros aspectos, na gestão democrática que congrega planejamento, gestão e controle social e orienta a adequação dos instrumentos de política econômica, tributária, financeira e dos gastos públicos para desenvolver as cidades (PINHEIRO, 2010).

Dessa forma, o Plano Diretor de um município é um documento que serve para orientar a arrecadação e a despesa qualificando o gasto público e que possibilita elementos concretos para compor as peças orçamentárias dos municípios (REZENDE, 2007). A valorização do PDM não está apenas ligada à implementação da função social da propriedade conforme a Constituição de 1988.

Para Rezende (2007) outro fenômeno que explica a valorização contemporânea de um PDM é, mais uma vez, a Constituição Federal, agora ao adotar uma política de descentralização político-administrativa, assim como uma valorização do ente municipal, que necessita ser capacitado e possuidor de bases técnicas referenciais para sua gestão (REZENDE, 2007). O autor explica que as questões físico-territoriais, econômicas, financeiras, políticas, socioambientais e de gestão têm constantemente desafiado os municípios, requerendo um avanço nas técnicas de planejamento até então desenvolvidas pelo governo local (REZENDE, 2007). Equilibrar os diferentes interesses que se apresentam em cada uma dessas temáticas e garantir a efetiva participação comunitária parece ser o desafio maior da administração pública local. (REZENDE, 2007).

Para Guedes (2012) antes de se analisar qualquer questão sobre as três leis que compõem o processo orçamentário, é necessário destacar que o Plano Diretor deve ser a base de informações para o desenvolvimento desse processo. O artigo 40, parágrafo único do Estatuto da Cidade estabelece a referência que liga o Plano Diretor às leis do processo orçamentário onde está definido que o Plano Diretor, aprovado por lei municipal, é o instrumento básico da política de desenvolvimento e expansão urbana (BRASIL, 2001). O parágrafo $1^{\circ}$ desta Lei estabelece que o PDM é parte integrante do processo de planejamento municipal, devendo o plano plurianual, as diretrizes orçamentárias e o orçamento anual incorporar as diretrizes e as prioridades nele contidas. 


\section{Democracia e Orçamento Participativo}

O princípio da descentralização administrativa e política também incluiu os municípios, como se vê em seu artigo 18, caput e $\S 4^{\circ}$ da CF/88. Portanto, segundo Salles (2010) rompendo com uma tradição oriunda do Período Colonial, a Constituição de 1988 fez dos municípios entes autônomos, equiparando-os à União e aos Estados. Mas, no final da década de 1990, o aprofundamento da municipalização resultou de iniciativas do Governo Federal no sentido de transformar os governos locais nos principais responsáveis pelos serviços universais de saúde e de educação fundamental e pelos seus gastos correspondentes (SALLES, 2010). Isso se deu porque de acordo com Salles (2010) no município é mais fácil garantir a responsabilização ou accountability.

Na visão de Raupp e Pinho (2013), uma noção mais restrita de accountability considera somente os mecanismos de controle formalizados e institucionalizados como capazes de exigir a responsabilização dos agentes públicos pelos atos praticados, enquanto uma noção mais abrangente considera, por sua vez, além dos mecanismos formais e institucionalizados, também mecanismos informais (RAUPP e PINHO, 2013).

Dessa forma, a participação dos cidadãos no processo decisório do ente governamental é uma dimensão da accountability tão importante quanto a prestação de contas e a transparência (Raupp e Pinho, 2013). A CF/88 enuncia em seu artigo 14 que a democracia se configura quando a população participa das decisões do ente federado através de institutos próprios como o plebiscito, o referendo e a iniciativa popular (BRASIL, 1988).

Quando os munícipes participam diretamente de reuniões públicas incentivadas pelo Poder Executivo tem-se uma forma peculiar de democracia participativa não especificada na CF/88, o chamado orçamento participativo (SALLES, 2010). A participação das organizações da sociedade importa porque ela complementa a representação. Salles sintetiza a questão anotando que

A existência de mecanismos de participação mantém os cidadãos ativos, atentos, mobilizados nos interstícios eleitorais. Os conselhos responsáveis pela democratização das políticas sociais contribuíram para o resgate da "dívida social", um dos compromissos da redemocratização. Entre elas destacamos: a Lei Orgânica da Saúde, a Lei Orgânica da Assistência Social, o Estatuto da Criança e do Adolescente e, mais recentemente, o Estatuto da Cidade. (SALLES, 2010, p. 49). 
A criação de espaços públicos de arranjos participativos para a realização de debate democrático e de tomada de decisões na compreensão de Salles (2010) pode tanto potencializar a representação e a participação como pode bloquear essa possibilidade, considerando os diversos constrangimentos que dificultam o funcionamento desses espaços públicos. Salles (2010) aponta que o planejamento se inscreve também no conjunto de medidas necessárias a uma gestão democrática e participativa e o orçamento, sendo uma peça política por excelência tem o condão de distinguir entre gestões autoritárias e democráticas.

\section{Orçamento Público}

O orçamento público não é um amontoado de números que todo ano se repete com correções de 5\% ou 10\% para cada dotação. Para Guedes (2012) o planejamento público é essencial para que haja uma boa administração e deve orientar as receitas e as despesas orçamentárias. Segundo estudo publicado pelo Conselho Regional de Contabilidade de Goiás (1996), o interesse popular pela gestão dos recursos públicos, no Brasil, teve sua origem na época da prosperidade colonial, quando surgiram lideranças nos diversos segmentos sociais, que traziam os ideais democráticos assimilados em seus estudos no Velho Mundo.

De acordo com Bezerra Filho (2013) praticamente não houve realização de trabalhos técnicos sobre Finanças Públicas nos períodos Colonial e Imperial, ao passo que na fase republicana, foram observados fatos relevantes sobre o tema, abrangendo os controles e os sistemas de orçamento e Contabilidade Pública como:

A sanção da Lei 4.320/1964 que instituiu as normas de Direito Financeiro e Contabilidade Pública; a CF de 1988; a EC n 19/1988 que inseriu o princípio da eficiência no caput do artigo 37 da CF/1988; a LC $\mathrm{n}^{\circ} 101 / 2000$ que estabeleceu normas de finanças públicas voltadas para a responsabilidade na gestão físcal, em conformidade com o artigo 163, I, da CF/88; a Lei $\mathrm{n}^{\circ} 10.028 / 00$ que definiu crimes vinculados ao desrespeito à responsabilidade fiscal. (BEZERRA FILHO, 2013, p. 27).

Ressalte-se, com o advento da LRF, à Secretaria do Tesouro Nacional, órgão central de contabilidade da União, cabe a edição de normas gerais para a consolidação das contas 
públicas, enquanto não for implantado o Conselho de Gestão Fiscal, previsto no artigo 67 da LC 101/00. Ao tratar de orçamento público, Bezerra Filho (2013) entende que:

O orçamento é ferramenta legal de planejamento do Ente Federativo, onde são projetados os ingressos e os gastos orçamentários que serão realizados em um determinado período, objetivando a execução dos programas e ações vinculados às políticas públicas, bem como as transferências constitucionais, legais e voluntárias, os pagamentos de dívidas e outros encargos inerentes às funções e atividades estatais (BEZERRA FILHO, 2013, p. 9).

Na visão de Prux, Balsan e Moura (2012), a sociedade tem o direito e o dever de participar da elaboração dos instrumentos de planejamento da vida do Estado. Pode participar das reuniões de elaboração e apreciação, pois somente assim será garantida uma governança democrática, que melhor atenda às necessidades da comunidade. A sociedade deve também participar da deliberação que aloca recursos públicos para a execução do programa de trabalho do governo de sua unidade federativa (BRASIL, 2010).

Segundo Mileski (2003) o orçamento público precisa ser objeto de participação popular e acompanhamento por parte da sociedade por ser o principal instrumento de execução da política fiscal. Para que os recursos sejam, de fato, destinados a atender as necessidades da população, além de participar da elaboração do orçamento, a sociedade deve fiscalizar a aplicação desse dinheiro, zelando pela boa e correta destinação do dinheiro público (BRASIL, 2010).

No processo evolutivo do orçamento, Santos (2011) destaca que até hoje, a aprovação, o monitoramento, a fiscalização e a avaliação do Orçamento Público estão entre as principais funções do Poder Legislativo, sendo esse poder tão mais forte quanto mais efetivamente participe do processo orçamentário.

Bezerra Filho (2013) elenca como objetivos do Orçamento Público: a) o controle de gastos para evitar abusos; b) a gestão de recursos considerando ações, produtos e metas; c) o planejamento com a implementação de plano de médio prazo; e d) a administração macroeconômica com vistas à distribuição de renda e ao crescimento econômico.

Dessa forma, evidenciam-se as funções do orçamento quando o gestor público busca manter a estabilidade econômica, alocar recursos e distribuir renda. Assim, o Orçamento público não é apenas uma formalidade para se viabilizar a realização de ações, é um 
instrumento que foi desenvolvido ao longo do tempo para apoiar um valor sociopolítico fundamental: a gestão transparente e democrática dos recursos públicos (Santos, 2011).

\section{As Peças Orçamentárias}

O sistema orçamentário brasileiro é regido pelo disposto na CF de 1988 que, em seu artigo 165, dispõe que leis de iniciativa do Poder Executivo estabelecerão o plano plurianual PPA, as diretrizes orçamentárias - LDO e os orçamentos anuais - LOA (BRASIL, 1988). O PPA constitui uma das novidades da nova Carta Magna e representa uma síntese dos esforços e planejamento de toda a administração pública, orientando a elaboração dos demais programas de governo (Giacomoni, 2012). Para Souza (2015), a lei de diretrizes orçamentárias estabelece metas, prioridades, metas fiscais e orientará a elaboração da proposta orçamentária.

\section{Plano Plurianual - PPA}

Na União, o Projeto do PPA é enviado pelo presidente da República ao Congresso Nacional, até 31 de agosto do primeiro ano de seu mandato, sendo devolvido para sanção até o encerramento da sessão legislativa (22 de dezembro). Bezerra Filho (2013) salienta que ainda não existe regulamentação dos padrões mínimos que devem conter um PPA, porém o autor destaca que, ao elaborar o Projeto de Lei, o governante deve considerar a identificação dos problemas, o estabelecimento de diretrizes e objetivos, o levantamento dos programas, ações, produtos gerados, metas físicas e estimativas de custos.

\section{Lei de Diretrizes Orçamentárias - LDO}

Na União, o Projeto de LDO é enviado anualmente pelo Presidente da República ao Congresso Nacional até o dia 15 de abril, e devolvido para sanção presidencial até o dia 17 de julho, sem o que o Congresso está impedido de iniciar o seu recesso de julho (art. $35, \S 2^{\circ}$, II, 
ADCT). Essa lei, de acordo com Bezerra Filho (2013), compreende metas e prioridades da Administração Pública Federal, incluindo as despesas de capital para o exercício financeiro subsequente, orienta a elaboração da LOA, dispõe sobre as alterações na legislação tributária e estabelece a política de aplicação das agências financeiras oficiais de fomento.

\section{Lei Orçamentária Anual - LOA}

O Projeto de LOA é enviado anualmente pelo Presidente da República ao Congresso Nacional, até o dia 31 de agosto, e devolvido para sanção presidencial até o dia 22 de dezembro (art. 35, $\S 2^{\circ}$, III, ADCT). Bezerra Filho (2013) ressalta que é com base nas autorizações da LOA que as despesas do exercício são executadas e que a LOA compreenderá o orçamento fiscal, da seguridade social e o de investimentos.

\section{Estado de Pernambuco e Municípios: prazos constitucionais a partir de 2008 para as peças orçamentárias}

Segundo Bezerra Filho (2013) enquanto não for aprovada a Lei Complementar prevista no $\S 9^{\circ}$ do art. 165 da Constituição Federal, os prazos de envio dos projetos das leis do PPA, LDO e LOA dos Estados e Municípios, por parte do Poder Executivo e do Poder Legislativo, respectivamente, podem ser diferentes daqueles previstos no $\S 2^{\circ}$ do art. 35 do ADCT, devendo estar disciplinados nas Constituições Estaduais ou Municipais, as leis Orgânicas. No caso de Pernambuco, o texto da Constituição estadual (1989) determina no art. 124 que os projetos de lei relativos ao PPA, a LDO e a LOA serão enviados à Assembleia Legislativa nos prazos fixados em lei complementar conforme segue:

\footnotetext{
$\S 1^{\circ}$ A partir do exercício de 2008, o Estado e os Municípios, até a vigência de Lei Complementar Federal, a que se refere o art. 165, § $9^{\circ}$, I e II, da Constituição da República Federativa do Brasil, observarão o seguinte: I - o projeto de lei de Diretrizes Orçamentárias será encaminhado ao Poder Legislativo, até o dia $1^{\circ}$ de agosto, de cada ano, e devolvido para sanção, até 31 de agosto de mesmo ano; II - o projeto de lei do Plano Plurianual será encaminhado, ao Poder Legislativo, até o dia 5 de outubro do primeiro exercício de cada mandato e devolvido para sanção, até o dia 5 de dezembro do mesmo ano. III - os projetos de Lei Orçamentárias Anuais do
} 
Estado e dos Municípios serão encaminhados ao Poder Legislativo e às Câmaras Municipais, respectivamente, até o dia 5 de outubro, de cada ano, e devolvido para sanção, até o dia 5 de dezembro do mesmo ano. (PERNAMBUCO, 1989, p. 72).

\section{Publicidade e Transparência fiscal: da obrigatoriedade à accountability}

O princípio da publicidade apresenta uma dupla acepção em face do sistema decorrente da Constituição de 1988 e nas lições de Alexandrino e Paulo (2015) é exigência de publicação oficial, como requisito de eficácia, dos atos administrativos que devam produzir efeitos externos e dos atos que impliquem ônus para o patrimônio público; exigência de transparência da atuação administrativa. Note-se que a Lei 12.527/2011, regulamentada no âmbito do Poder Executivo federal pelos Decretos 7.724/12 e 7.845/12, disciplina os dispositivos constitucionais do inciso XXXIII do art. $5^{\circ}$, inciso II do $\S 3^{\circ}$ do art. 37 e $\S 2^{\circ}$ do art. 216 que deixam bem clara a exigência de atuação transparente de toda a administração pública (ALEXANDRINO e PAULO, 2015).

Desde a virada do século $\mathrm{XX}$, observa-se um aumento na criação do número de municípios, o que acarreta a deterioração da qualidade dos serviços públicos. Perez, Lima e Sartorelli (2015) apontam inúmeros problemas que afetam a Administração Pública com a proliferação de municípios criando ambiente propício ao descontrole das contas públicas e ao desatendimento das necessidades da população, o que justifica a promulgação da Lei de Responsabilidade Fiscal (2000) para coibir tal descontrole e da Lei 12.527/11, que visa à transparência fiscal baseada na ideia de que a publicação da destinação dos recursos públicos possa permitir o acompanhamento e avaliação dos cidadãos (PEREZ, LIMA e SARTORELLI, 2015).

Extrai-se do princípio da publicidade que o povo tem o direito de conhecer os atos praticados na administração pública, passo a passo, para o exercício do controle social, derivado do exercício do poder democrático. De acordo com Platt Neto et al (2007), o ordenamento jurídico prevê várias normas que disciplinam a prestação de contas dos gestores públicos ao poder público e à comunidade em geral. $\mathrm{O}$ artigo $70 \mathrm{da} \mathrm{CF} / 88$, em seu parágrafo único, define quem tem a obrigação de prestar contas. Sampaio et al. (2014) destaca ser fundamental a participação popular na construção da matriz orçamentária para assegurar a 
transparência pública, a cobrança social quanto à aplicação dos recursos em várias áreas como saúde, educação, segurança, lazer e cultura.

Para Platt Neto et al (2007), no Brasil, a transparência é considerada um princípio da gestão fiscal responsável que deriva do princípio constitucional da publicidade. Todavia, a transparência é um conceito mais amplo que a publicidade, isso porque uma informação pode ser pública, mas não ser relevante, confiável, oportuna e compreensível. Portanto, a compreensibilidade dos dados e das informações pelos usuários é uma condição indispensável. A LC 101/00 visa auxiliar no ajuste fiscal para os entes federados contemplando os aspectos sintetizados a seguir:

Imposição de limites de gastos; estabelecimento do equilíbrio entre receitas e despesas; controle dos custos com programas de governo; limitação da expansão de despesas obrigatórias, estabelecendo e analisando os passivos contingentes, demonstrando isenções e benefícios tributários, limitando despesas com pessoal e seguridade social; além de atribuição de responsabilidade aos gestores e o estabelecimento do processo de fiscalização dos entes da federação pelos tribunais de contas.(PEREZ, LIMA e SARTORELLI, 2015, p. 6).

O artigo 48 da LC 101/00 prevê a obrigatoriedade de divulgação dos chamados instrumentos de transparência fiscal como os planos, orçamentos e leis de diretrizes orçamentárias; as prestações de contas e o respectivo parecer prévio; o Relatório Resumido da Execução Orçamentária e o Relatório de Gestão Fiscal; e as versões simplificadas desses documentos (BRASIL, LC 101/2000). A estes deveria ser dada ampla divulgação, como salientam Perez, Lima e Sartorelli (2015), inclusive em meio eletrônico e acesso público (BRASIL, LC 101/2000), expressão que inclui o meio eletrônico, mas não a torna a forma exclusiva (PEREZ, LIMA e SARTORELLI, 2015).

A LRF obriga o chefe do Poder Executivo, expressamente nos termos dos artigos 48 e 49, a praticar a publicidade divulgando as peças orçamentárias com objetivos e metas fiscais e os relatórios atinentes à prestação de contas. Segundo Lyrio e Lunkes (2014), cabe aos gestores públicos incentivar e praticar a divulgação das informações além do que é solicitado como um dever de informar o cidadão sobre o andamento da gestão governamental.

A transparência na gestão fiscal é o principal instrumento para o controle social. Assim, além de atender à obrigatoriedade legal brasileira sobre publicidade e transparência fiscal, o gestor público municipal estará prestando contas à população. Em outros termos, ao 
Id on Line Revista Multidisciplinar e de Psicoloqia

Id on Line Multidisciplinary and Psycology Journal

desenvolver uma gestão pública transparente, o chefe do Poder Executivo terá a obrigatoriedade de exercer um governo responsável porque o mesmo entende que a participação dos cidadãos no processo decisório do ente governamental é uma dimensão da accountability, que é uma forma de responsabilização tão importante quanto a prestação de contas e a transparência.

\section{Resultados}

A coleta de dados do estudo concentra-se nos portais das prefeituras dos sete municípios integrantes da microrregião de Salgueiro-PE, considerando o primeiro semestre de 2017 como recorte temporal. Conforme o Gráfico 1, foram analisados os portais das prefeituras de Cedro, Mirandiba, Parnamirim, Salgueiro, São José do Belmonte, Serrita e Verdejante, dos quais cinco possuem populações abaixo de 20 mil habitantes, superando esse número apenas os municípios de São José do Belmonte e Salgueiro, segundo o último censo (2011) do IBGE.

Gráfico 1 - População dos municípios da microrregião de Salgueiro censo 2011 do IBGE

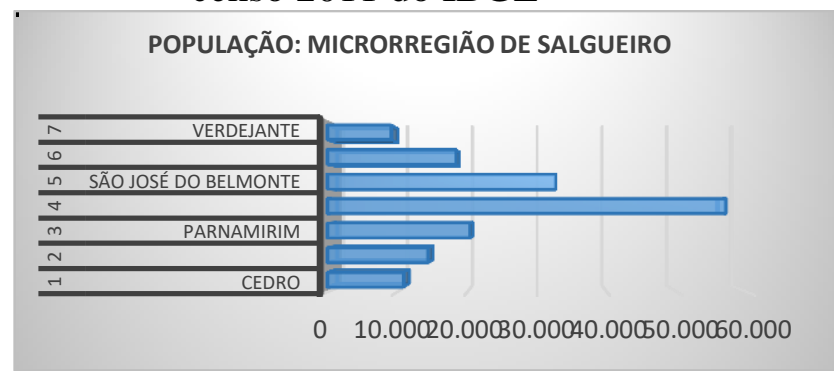

Fonte: Elaborado pelos Autores

A LC 101/00 aponta que os pequenos municípios são aqueles com menos de 50 mil habitantes, cerca de $90 \%$ dos municípios brasileiros, e que estão obrigados, nos termos da Lei, a partir de 2005, a publicizar os objetivos e metas fiscais de suas diretrizes orçamentárias com o anexo de metas fiscais para o triênio e a publicação dos Relatórios orçamentários com periodicidade que varia entre dois e seis meses, a depender do Relatório. 
No estudo, a identificação da população importa para evidenciar que não estão desobrigados a cumprir a Lei os municípios de Verdejante, Serrita, Parnamirim, Mirandiba e Cedro, em detrimento de São José do Belmonte e Salgueiro, que possuem população superior a 20 mil habitantes; pois, mesmo o Estatuto da Cidade incentiva que os pequenos municípios elaborem seus planos diretores a fim de instrumentalizar seu planejamento que, com o advento da LC 101/00, não isenta os pequenos municípios de praticarem a transparência fiscal.

A coleta dos dados extraiu do artigo 48 (LC 101/00) as categorias e subcategorias mensuradas no estudo e considera a disponibilização das peças orçamentárias (categoria 1) e a compreensibilidade-interatividade por parte dos munícipes (categoria 2). Tais categorias compõem as etapas iniciais (obtenção e compreensibilidade de informações) constantes no estudo de Perez, Lima e Sartorelli (2015).

Para análise do nível de aderência dos municípios às categorias extraídas por esse estudo do caput do artigo 48 da LC 101/00 recorre-se ao barema elaborado por Braga (2015) para pontuar as subcategorias, que integram as duas categorias pesquisadas, avaliadas através de uma escala estruturada de três pontos (Figura 1) segundo os critérios a seguir:

(0) zero ponto para o não atendimento do item;

(1) um ponto para atendimento parcial, como por exemplo, o ícone no sítio virtual com identificação da peça orçamentária, mas o município disponibiliza o documento desatualizado, incompleto; e,

(2) dois pontos para atendimento integral das exigências legais.

Figura 1- Escala Estruturada com avaliação de três pontos

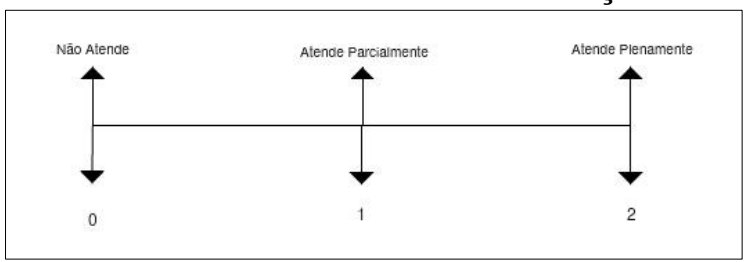

Fonte: Braga, 2015 
A categoria 1 se desdobra em duas subcategorias: obtenção e download de informações (PPA, LDO, LOA) e a categoria 2 se desdobra em quatro subcategorias: legendas e arquivos explicativos, orçamento participativo e FAQ (Frequently Asked Questions).

A categoria 1 tem como objeto de coleta as peças de orçamentação nos sítios virtuais das prefeituras dos municípios da microrregião de Salgueiro e a categoria 2 busca, nestes sítios virtuais, registros/arquivos/indicativos que facilitem a compreensão e a participação da população no processo de publicidade e transparência fiscal dos municípios, conforme se ilustra na Tabela 1.

Tabela 1 - Categorias e subcategorias para mensuração do nível de aderência à legislação.

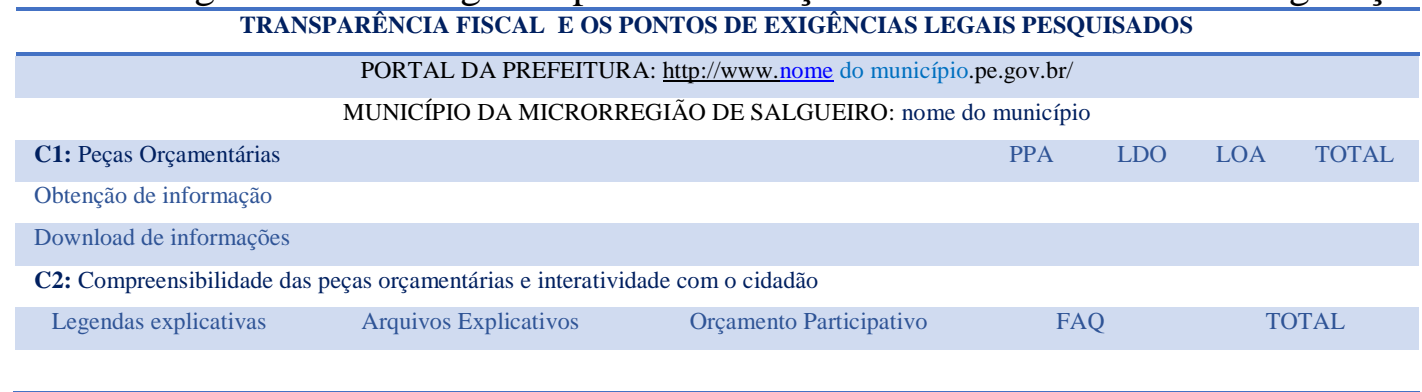

Fonte: Elaborada pelos Autores

Para cada município, foi preenchida a tabela de categorias a partir da qual é gerado o gráfico representativo do nível de aderência para cada município. Os resultados confirmam que a prestação de contas (accountability) à população não está seguindo as orientações mínimas legais.

Gráfico 02 -Nível de aderência às exigências legais de transparência físcal dos sítios virtuais das prefeituras da microrregião de Salgueiro

TRANSPARÊNCIA FISCAL E OS PONTOS DE EXIGÊNCIAS LEGAIS PESQUISADOS MICRORREGIÃO DE SALGUEIRO - PE

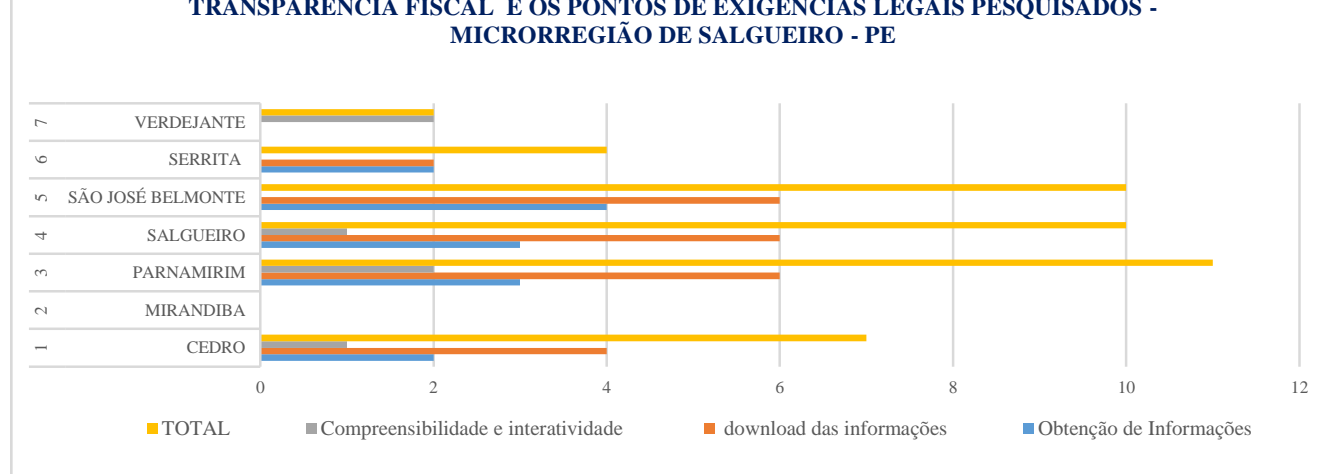

Fonte: Elaborado pelos Autores 
O Gráfico 02 apresenta os resultados encontrados nas buscas aos sítios virtuais dos sete municípios da microrregião de Salgueiro. Os resultados apontam que tais sítios virtuais possuem baixíssima aderência às normas legais para publicidade e transparência fiscal: dos sete municípios Mirandiba não pontua em nenhuma das categorias pesquisadas, não registrando pontuação alguma na elaboração do Gráfico 02 , ao passo que o município de Parnamirim apresenta um sítio virtual que atende de forma mais consistente à obrigatoriedade normativa, perfazendo a maior pontuação entre os sete municípios desta microrregião; no entanto, no site da prefeitura de Parnamirim a obtenção das informações é referente à gestão municipal anterior; os arquivos/registros para facilitar a compreensão e participação popular carecem ser melhorados.

Em posição intermediária no Gráfico 02, aparecem São José do Belmonte, Salgueiro e Cedro pontuando, mas com dados pouco consistentes para favorecer a construção de um processo orçamentário que contemple a compreensão e participação de suas populações. Em posição crítica, aparecem Serrita e Verdejante que apresentam insuficiência de dados, que comprometem seu nível de aderência normativa a um processo orçamentário consistente e uma gestão fiscal transparente e responsável.

\section{Considerações Finais}

O estudo considera que o controle social da arrecadação e despesa públicas não deve se apresentar de difícil acesso a sua população e, para tanto, os administradores públicos devem buscar formas de aproximar a população da execução e controle do gasto público através de ferramentas de planejamento e orçamentação. Dessa forma, a divulgação e publicidade das peças orçamentárias se mostram como necessidades intrínsecas à Administração Pública.

Uma vez que o PPA traz o diagnóstico, as diretrizes, os objetivos e as ações de cada programa, que motiva a arrecadação e justifica a despesa pública, a disponibilização das peças orçamentárias pelos entes federados se presta ao acompanhamento popular, como reflexo de uma administração transparente e em consonância com a legislação contemporânea brasileira. 
Assim, buscou-se investigar como os municípios divulgam as suas peças orçamentárias nos sítios virtuais das prefeituras da microrregião de Salgueiro conforme a legislação brasileira. Os resultados encontrados no estudo revelam que a microrregião de Salgueiro possui baixíssima aderência à orientação legal para publicização de suas peças orçamentárias, o que compromete o nível de transparência físcal a ser praticado pelos municípios integrantes da microrregião pesquisada.

Dessa forma, com a obrigatoriedade comprometida pela não divulgação ou divulgação parcial de informações/dados sobre o processo orçamentário nos sítios virtuais de suas prefeituras, os municípios da microrregião de Salgueiro comprometem outro processo importante na gestão pública: a accountability, entendida no contexto do estudo como a necessária prestação de contas à população.

O estudo revela uma situação crítica no que tange à publicização do PPA, da LDO e da LOA nesses municípios, que compõem uma região de desenvolvimento importante no sertão central de Pernambuco. As informações sobre as peças e todo o processo orçamentário nos sites das prefeituras da microrregião de Salgueiro são de difícil compreensão, escassas, desatualizadas, insuficientes, equivocadas por vezes. Há muito mais confusão do que orientação nos sites das prefeituras pesquisadas, o que torna o acompanhamento e a compreensão do processo orçamentário pelo usuário uma tarefa árdua e infértil.

Os resultados apontam dois extremos que confirmam que não há unidade na microrregião de Salgueiro quando o assunto é orçamento público: de um lado o município de Mirandiba não pontua em nenhuma das categorias básicas pesquisadas; de outro, o município de Parnamirim dá sinais de estar construindo um portal virtual mais próximo às exigências mínimas legais no que se refere ao processo orçamentário e à transparência fiscal.

Assim, o estudo recomenda o aprofundamento do tema em pesquisas futuras para ampliar o entendimento de outros aspectos legais não investigados e ligados ao orçamento público no que diz respeito aos sítios virtuais dos sete municípios da microrregião de Salgueiro, com a finalidade de oferecer subsídios para que a microrregião supere o baixíssimo nível de aderência às normas brasileiras para a promoção da publicidade e transparência na gestão dos recursos públicos. 


\section{Referências}

ALEXANDRINO, Marcelo. PAULO, Vicente. Direito Administrativo descomplicado. $23^{\text {a }}$ ed. - Rio de Janeiro: Forense; São Paulo: Método, 2015.

BEZERRA FILHO, João Eudes. Orçamento aplicado ao setor público: abordagem simples e objetiva. 2. ed. São Paulo: Atlas, 2013.

BRAGA, Ivaneide Almeida. Convergência às NBCASP e ao MCASP: um estudo sobre os municípios pernambucanos em 2014. Disponível em <http://congressos.anpcont.org.br/x/anais/files/2016-05/cpt73.pdf> Acesso em 25-8 de maio de 2017.

BRASIL. Constituição da República Federativa do Brasil, promulgada em 5 de outubro de 1988. Disponível em: <http://www.planalto.gov.br/ccivil_03/constituicao/ constitui\%C3\%A7ao.htm>. Acesso em: 26 maio 2010.

Estatuto da Cidade: guia para implementação pelos municípios e cidadãos. 4. ed. Brasília: Instituto Pólis/Laboratório de Desenvolvimento Local, 2005. Disponível em: <http://www.senado.gov.br/sf/publicacoes/ estatuto/estatutodacidade.pdf >. Acesso em: 31 maio 2010.

Lei de Responsabilidade Fiscal. Lei Complementar $n^{\circ}$ 101, de 4 de maio de 2000. Estabelece normas de finanças públicas voltadas para a responsabilidade fiscal e dá outras providências.

Fiscal.

Lei Complementar $\mathbf{n}^{\mathbf{0}}$ 12.527, de 18 de novembro de 2011 - Lei de Transparência

Presidência da República. Olho vivo no dinheiro público: Controle Social: orientações aos cidadãos para participação na gestão pública e exercício do controle social. Brasília: Controladoria Geral da União, 2010.

CONSELHO REGIONAL DE CONTABILIDADE DE GOIÁS. Ensaios de contabilidade orçamentária. Goiânia: CRC-GO, 1996.

GIACOMONI, J. Orçamento Público. 16. ed. São Paulo: Atlas, 2012.

GUEDES, ODILON GUEDES. Orçamento Público e Cidadania. Disponível em $<$ https://marialuizalevi.files.wordpress.com/2016/06/livro-odilon-guedes.pdf> Acesso em 27/03/17.

JACOBSEN, Alessandra de Linhares. MORETTO NETO, Luís. Teorias da Administração II - 2. ed. reimp. - Florianópolis: Departamento de Ciências da Administração / UFSC, 2012. 
JUNQUILHO, Gelson Silva. Teorias da Administração Pública. 2. ed. Florianópolis: Departamento de Ciências da Administração/UFSC: CAPES: UAB, 2012.

LRF: CARTILHA Disponível em <http://www.planejamento.gov.br/> Acesso: 27 de maio de 2017.

LYRIO, Maurício Vasconcellos Leão. LUNKES, Rogério João. A transparência dos portais das prefeituras em municípios catarinenses sob a perspectiva da legislação brasileira. Disponível em <http://revistas.una.br/index.php/reuna/article/view/566 $>$ Acesso em maio de 2017.

MILESKI, H. S. O Controle da Gestão Pública. São Paulo: Editora Revista dos Tribunais, 2003.

PEREZ, Yuri Vieira. LIMA, Ayumi Kuroda da Silva. SATORELLI, Isabel Cristina. Transparência fiscal e controle social: análise do entorno do município de Sorocaba. Disponível em <http://congressos.anpcont.org.br/ix/anais/artigo/cpt-191-transparencia-fiscale-controle-social-analise-do-entorno-do-municipio-de-sorocaba> Acesso em maio de 2017.

PERNAMBUCO. Constituição de Pernambuco. Disponível em $<$ http://legis.alepe.pe.gov.br/arquivoTexto.aspx?tiponorma=12\&numero=1989\&complemento $=0 \&$ ano $=1989 \&$ tipo $=\&$ url $=>$ Acesso em 15/05/2017.

PINHEIRO, Otilie Macedo. Plano diretor e gestão urbana. Florianópolis: Departamento de Ciências da Administração / UFSC; [Brasília]: CAPES: UAB, 2010.

PIOVESAN, Armando. TEMPORINI, Edméa Rita. Pesquisa exploratória: procedimento metodológico para o estudo de fatores humanos no campo da saúde pública. Disponível em <http://www.scielo.br/pdf/rsp/v29n4/10.pdf> Acesso em 06/03/2017

PLATT NET, Orion Augusto et al. Publicidade e Transparência das Contas Públicas: Obrigatoriedade e Abrangência desses Princípios na Administração Pública Brasileira. Disponível em <http://revistas.face.ufmg.br/index.php/contabilidadevistaerevista/article/view/320 > Acesso em maio de 2017.

PRUX, Paula Raymundo. BALSAN, Laércio André Gassen. MOURA, Gilnei Luiz de. Transparência e participação popular nas audiências públicas de elaboração e discussão

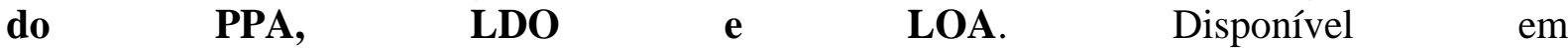
$<$ http://www.eumed.net/rev/cccss/22/elaboracion_discusion_ppa_ldo_loa.html $>$ Acesso em abril e maio de 2017.

RAUPP, Fabiano Maury. PINHO, José Antonio Gomes. Accountability em câmaras municipais: uma investigação em portais eletrônicos. Disponível em <http://ac.elscdn.com/S0080210716303077/1-s2.0-S0080210716303077-main.pdf?_tid=ed6fc510-223511e7-8413-00000aacb35f\&acdnat=1492300247_2cdf1a525ad852c9d3b86bef5093b449> Acesso em 15/04/17. 
REZENDE, Denis Alcides. ULTRAMARI, Clovis. Plano diretor e planejamento estratégico municipal: introdução teórico-conceitual. Disponível em <http://www.scielo.br/scielo.php?script=sci_arttext\&pid=S0034-76122007000200005> Acesso em 21/03/2017.

RICHARDSON, Roberto Jarry et al. Pesquisa Social: métodos e técnicas. São Paulo: Atlas, 1999.

SALLES, Helena da Motta. Gestão Democrática e Participativa. 2010. Florianópolis: Departamento de Ciências da Administração / UFSC; [Brasília]: CAPES: UAB, 2010.

SAMPAIO, Francisco Jean Carlos de Souza et al. Orçamento Participativo: a experiência do município paraibano na implantação de uma ferramenta de construção coletiva para implementação de políticas públicas. Disponível em < http://cbc.cfc.org.br/comitecientifico/images/stories/slides/501C.pdf >Acesso em abril e maio de 2017.

SANTOS, Rita de Cássia Leal Fonseca dos. Orçamento Público. Departamento de Ciências da Administração - UFSC: Florianópolis: Brasília: CAPES: UAB, 2011.

SOUZA, Ronnye Oliveira. Participação no processo orçamentário (PPA, LDO, LOA) por meio de aplicativos móveis: uma proposta para o Governo do Estado de São Paulo. Disponível em <http://gvpesquisa.fgv.br/teses-dissertacoes/participacao-no-processoorcamentario-ppa-ldo-loa-por-meio-de-aplicativos-moveis> Acesso em abril e maio de 2017.

TRIGUEIRO, Francisco Mirialdo Chaves. MARQUES, Neiva de Araújo. Teorias da Administração I. - 2. ed. reimp. - Florianópolis: Departamento de Ciências da Administração / UFSC, 2012.

Como citar este artigo (Formato ABNT):

SOUSA, Luzania A.; OLIVEIRA, Cícero A.; OLIVEIRA, Júlio J.; GALVÃO, F.; CAFFÉ FILHO, Hesler P. Transparência Fiscal dos Sítios Virtuais das Prefeituras da Microrregião de Salgueiro: da obrigatoriedade à accountability. Id on Line Revista Multidisciplinar e de Psicologia, Julho de 2017, vol.11, n.36, p.124-145. ISSN: 1981-1179.

Recebido: 19.06 .2017

Aceito: 21.06 .2017 